\title{
Uso de agrotóxicos no Município de Cachoeiras de Macacu (RJ)
}

\author{
Pesticide use in Cachoeiras de M acacu, \\ Rio de Janeiro, Brazil
}

\footnotetext{
1 Universidade

Castelo Branco.

Av. Brasil 9.727,

Campus Penha, 21021-020,

Rio de Janeiro RJ.

janemaia@globo.com

2 Fundação Oswaldo Cruz.
}

Abstract It was surveyed the use of pesticides in 40 rural properties in the municipality of $\mathrm{Ca}$ choei ras de M acacu, State of Rio de Janeiro, in 1997. The collection of data in the field was done through the use of questionnaires with rural workers as well as through interviews with authorities. The survey showed that $22,5 \%$ of the farm workers have suffered chemical intoxication. The most common agrochemical products in the region are the insecticide Decis 25 CE (highly toxic), and the herbicide Gramoxone (extremely toxic). We also found that $85 \%$ of the farm workers do not use Individual Protection Equipment (IPE). 0 ther preoccupying statistics were: $27,5 \%$ of the empty agrochemical containers are simply thrown into the rivers or into the bush; $60 \%$ of the farm workers have had no training whatsoever in manipulation of the agrochemical products; and, $85 \%$ of those interviewed said that they were able to buy the agrochemical products without an agronomic prescription. As to the perception of the risks involved in manipulating agrochemicals, we identified three major categories: $70 \%$ are aware of the danger, but continue regardless; $27 \%$ are unaware of the risks; are, $3 \%$, being aware of risks, have stopped using toxic agrochemicals.

Key words U se of pesticides, Public health, Rural workers, Risk perception
Resumo 0 artigo apresenta um levantamento efetuado no ano de 1997 em 40 propriedades rurais de Cachoeiras de M acacu (RJ) acerca da percepção de risco e das práticas de uso dos agrotóxi$\cos$. A pesquisa de campo foi feita com agricultores (40 questionários) e com autoridades (entrevistas abertas) . A análise dos resultados demonstrou que $22,5 \%$ dos agricultores reportaram já terem sido intoxicados por agrotóxico, sendo o inseticida Decis 25 CE eo herbicida Gramoxone (ambos extremamente tóxicos) os mais utilizados na região. Verificou-se que $85 \%$ dos agricultores não utilizavam Equipamentos de Proteção Individual (EPI), que $27,5 \%$ jogavam embalagens de agrotóxicos no rio ou no mato, que $60 \%$ de entrevistados nunca foram treinados para manusear agrotóxicos e que $85 \%$ disseram não precisar de receituário agronômico para comprá-los. Quanto à percepção do risco do uso de agrotóxicos, foram identificadas três categorias: 70\% percebem, mas continuam usando; $27 \%$ não percebem o risco; $3 \%$ percebem e não utilizam mais. Discutem-se as razões para estas práticas de risco, comparando-se com achados de outros autores.

Palavras-chave U so de agrotóxicos, Saúde pública, Trabalhador rural, Percepção de risco 


\section{Introdução}

Os agrotóxicos são substâncias que, apesar de serem cada vez mais utilizadas na agricultura, podem oferecer perigo para o homem, dependendo da toxicidade, do grau de contaminação e do tempo de exposi ção durante sua aplicação.

Em muitos países, principalmente naqueles em desenvolvimento, o uso indiscriminado dos agrotóxicos é generalizado e tem chamado a aten ção dos governos, das agências de proteção do meio ambiente e de trabalhadores. I gbedioh (1991), em seu estudo, relata que a exposição aos agrotóxicos por longo tempo em homens, plantas e animais tem efeitos nocivos e indesejáveis. A ponta como medidas para redução de riscos na sua utilização: a educação e treinamento dos agricultores, a regulação da propaganda, a limitação do uso de substâncias altamente tóxicas, o monitoramento da população mais exposta ao agrotóxico e a inspeção dos produtos nas lojas de venda e no campo.

Segundo Trapé (1993), ocorreram no mundo cerca de três milhões de intoxicações agudas por agrotóxicos, com 220 mil mortes por ano. Destas, cerca de $70 \%$ se dão em países do chamado Terceiro M undo. Além da intoxicação dos trabalhadores que têm contato direto ou indireto com esses produtos, a contaminação de alimentos tem causado intoxicações e mortes.

No Brasil, um fator se destaca na análise das informações sobre intoxicações e envenenamentos no meio rural - a distância, que dificulta 0 acesso dos trabal hadores aos centros de atendimento médico-hospitalar. Essa situação faz com que inúmeras vítimas de acidentes graves acabem morrendo sem qualquer assistência médica. 0 s acidentes mais leves acabam freqüentemente não sendo sequer comunicados ao Funrural (Fundação de Previdência ao Trabalhador Rural). Este fator é relevante para explicar a baixa incidência, apenas aparente, de acidentes leves entre os trabal hadores rurais (Bortoletto, 1990).

Outro fator a ser considerado na análise do sub-registro é a gravidade. M uitas vezes, as intoxicações por defensivos não são graves a ponto de exigir internação; e são freqüentes os casos em que os trabalhadores rurais, embora com sintomas de intoxicação, continuam sua jornada de trabalho sem procurar atendimento médico. M esmo para casos de intoxicações graves, a falta de atendimento médico é causa comum de sub-registro.
A informação e a notificação de intoxicações agudas produzidas por agrotóxicos continuam sendo deficientes no país devido à precária assistência médica na área rural e à semeIhança dos sintomas de intoxicação por agrotóxicos com os de outras doenças, segundo o Ministério da Saúde (1997).

Dados oficiais recentes colocam o Brasil como 070 consumidor mais freqüente no mundo, tendo sido consumidos no país, em 2001, 328.413 toneladas destes produtos (Anvisa, 2002).

Rozemberg (1994) realizou um estudo sobre o consumo de calmantes e os chamados "problemas de nervos" entre 93 lavradores, em 25 comunidades rurais da região serrana do Estado do Espírito Santo. Constatou que 30\% dos lavradores entrevistados se diziam com "problemas de nervos" e os principais sinais e sintomas descritos eram: tonteira e tremores, insônia, fraqueza e cansaço. Sintomas semeI hantes aos encontrados nas intoxicações por inseticidas organ ofosforados.

U ma pesquisa realizada pela Secretaria de Agricultura do Estado do Paraná (Siqueira et al., 1983) mostrou que, no período de agosto de 1982 a março de 1983, ocorreram cerca de 1.500 casos de intoxicações por agrotóxicos naquele Estado, dos quais 1.268 (84,5\%) na cultura de algodão. A faixa etária entre 20 e 30 anos foi a que apresentou o maior número de intoxicações. O utro dado importante se refere às tentativas de suicídio por ingestão de agrotóxicos, muito comuns no meio rural. De 41 casos constatados, 24 foram de óbito, representando $1,5 \%$ do total das pessoas intoxicadas. Também foi constatada a permanência de resíduos de agrotóxicos nos alimentos produzidos no Paraná.

Labont (1989) realizou uma pesquisa sobre o uso de agrotóxicos entre os fazendeiros no Canadá e verificou que, no ano de 1983, houve 3.404 casos de intoxicação entre os trabalhadores rurais, sendo que 1.458 fazendeiros foram hospitalizados.

M cConnel \& H ruska (1993) relataram um aumento epidêmico de intoxicações por pesticidas em uma área da N icarágua. D os 548 casos identificados em 1987, cerca de $91 \%$ se deveram à exposição ocupacional, geralmente em pequenas propriedades rurais (menos de 140 hectares). Atribuem 0 aumento de casos à falta de proteção individual na aplicação manual dos produtos, à autorização local para uso de substâncias altamente tóxicas e de uso restrito 
em vários países, bem como à existência de subsídios agrícolas que encorajam o uso de agrotóxicos.

Garry (1994) estudou 1.000 aplicadores de agrotóxicos em M innesota, nos Estados U nidos, e constatou que a diminuição da acetilcolinesterase era $20 \%$ mais freqüente nos aplicadores que pulverizavam os agrotóxicos em lugares fechados do que naqueles que o faziam em áreas abertas. Foi concluído nesse estudo que as doenças crônicas de pulmão também eram mais freqüentes nos aplicadores de agrotóxicos em lugares fechados.

M wanthi (1993) analisou, entre 1987 e 1990, os padrões de manuseio de agrotóxicos e as respostas comunitárias no Quênia, África. Os dados levantados demonstraram que apesar dos seus conhecimentos limitados sobre segurança no manuseio e armazenamento, $100 \%$ dos entrevistados usavam os agrotóxicos de forma intensiva. Acredita 0 autor que a falta de consciência dos indivíduos e da comunidade em relação aos riscos associados ao uso destas substâncias foi o fator que contribuiu para o aparecimento dos casos de intoxicações relatados.

M cD ougall (1993) estudou o uso de agrotóxicos e a percepção dos riscos para a saúde em agricultores na I lha de Santa Lúcia, no Caribe, onde observou que $60 \%$ dos entrevistados nunca usavam roupas de proteção e que $25 \%$ fumavam enquanto aplicavam os agrotóxicos.

Popper et al. (1993) analisaram o conhecimento dos riscos à saúde entre os fazendeiros e suas esposas na Guatemala, e identificaram que eles usavam produtos altamente tóxicos e que a dosagem dependia da quantidade de pragas sobre a terra e sobre as plantas. A maioria deles tinha um baixo conhecimento dos riscos de uso dos mesmos. A maior parte das donas de casa aplicava agrotóxicos para combater os piolhos em suas crianças, quando já tinha sido mencionado que esses produtos causavam problemas de saúde como náuseas, vertigem e dor de cabeça.

Stewart (1996) organizou uma pesquisa sobre as práticas do uso de agrotóxicos entre os trabal hadores rurais do Egito e observou que $58,2 \%$ desses agricultores não usavam equipamento de proteção, que somente $7,7 \%$ dos fazendeiros usavam luvas e que $42,5 \%$ dos entrevistados lavavam a embalagem do produto e a reutilizavam.

Sartorato (1996) analisou os riscos da aplicação de agrotóxicos em dois assentamentos rurais e constatou que a caracterização dos as- sentamentos se reflete nas semel hanças e dessemelhanças existentes no processo produtivo e também nas "visões do mundo" dos trabal hadores que produzem com agrotóxicos (em São J osé da Boa M orte, Cachoeiras de M acacu, RJ) e daqueles que produzem sem agrotóxicos (Eldorado, Seropédica, RJ). Observou-se que os lavradores de Eldorado, do assentamento Casas Altas, possuíam mais conhecimento sobre os riscos dos agrotóxicos para a saúde humana e ambiental do que os de São José da Boa M orte, que os utilizavam intensamente e não os associavam ao aumento de pragas e à produtividade reduzida.

Tinoco-Ojanguren \& $\mathrm{H}$ alperin (1998) observaram que no $M$ éxico os produtores rurais de subsistência apresentavam níveis menores de colinesterase sangüínea, indicando maior exposição aos inseticidas organofosforados do que os que adotavam outros sistemas de produção agrícola.

Guillette et al. (1998) constataram uma redução na capacidade mental, bem como um incremento do comportamento agressivo de crianças mexicanas de 4 a 5 anos de idade expostas aos agrotóxicos, em áreas de uso intensivo desses produtos (mais que 45 aplicações anuais).

Araújo et al. (2000) estudaram as práticas de uso de agrotóxicos em plantadores de tomate de duas localidades do Estado de Pernambuco. Em uma das localidades, observaram que as embalagens vazias dos produtos não tinham um destino estabelecido previamente $(44,5 \%)$ : ou eram enterradas no próprio local (37\%) ou eram armazenadas para queima posterior $(18,5 \%)$. $\mathrm{Na}$ outra localidade, os autores constataram que $13,2 \%$ dos agricultores já tinham sofrido algum tipo de intoxicação. Por outro lado, neste mesmo local, só $36 \%$ dos entrevistados utilizaram o Receituário Agronômico; apenas 13\% receberam instruções sobre a utilização dos produtos e $64,2 \%$ informaram que não faziam uso de equipamentos de proteção individual.

M oreira et al. (2001), em uma avaliação integrada do regime de uso de agrotóxicos no município de Nova Friburgo, no Estado do Rio de Janeiro, estudaram um grupo de agricultores expostos a mais de 100 produtos (adultose crianças). N otaram que $62,3 \%$ dos adultos e $38,6 \%$ das crianças não usavam equipamento de proteção e que $47,8 \%$ dos primeiros e $52 \%$ das crianças não haviam recebido nenhum tipo de treinamento para manipular agrotóxicos. 0 relato de aparecimento de sintomas após 0 
processo de aplicação foi de $47,8 \%$ nos adultos e $34 \%$ nas crianças.

Oliveira-Silva et al. (2001) analisaram amostras sangüíneas de um grupo de 55 agricultores do município de Magé, no Estado do Rio de Janeiro. U tilizando métodos enzimáticos para detecção de intoxicações por agrotóxicos anticolinesterásicos, observaram que cerca de $45 \%$ apresentavam sinais de intoxicação, mais comuns em indivíduos com baixa escolaridade.

\section{Material e métodos}

0 município está localizado na porção centrosul do Estado do Rio de Janeiro; limita-se ao norte com N ova Friburgo e Teresópolis, ao sul com Itaboraí e Rio Bonito, ao leste com Silva Jardim, e ao oeste com Guapimirim.

As localidades estudadas foram Papucaia, M arubai, São José da Boa M orte, Soarinho e Vecchi.

Utilizamos como metodologia a pesquisa qualitativa e a quantitativa. A combinação dessas metodologias permite a investigação das práticas de uso dos agrotóxicos, dos impactos causados na saúde e no ambiente, associandoos com dados subjetivos da percepção que a comunidade pesqui sada tem sobre essas práticas.

Empregamos, como instrumento de coleta de informação, dois tipos de entrevistas: aberta e semi-estruturada. As entrevistas abertas foram realizadas com os representantes do poder local (Secretaria M unicipal de M eio Ambiente, Agricultura e Saúde, Coordenação de Vigilância Sanitária e Emater - Empresa de Assistência Técnica e Extensão Rural - Escritório Local de Papucaia), gravadas em fitas cassete e transcritas. As entrevistas semi-estruturadas foram feitas com os agricultores através de questionários, por tratar-se de um número maior de entrevistados.

Os questionários foram aplicados durante as entrevistas, e divididos em dois segmentos para compreensão do objeto de estudo. No primeiro segmento, tabulou-se dados sobre o perfil socioeconômico-ambiental dos entrevistados e as suas práticas de uso dos agrotóxicos; no segundo segmento, mais qualitativo, investigou-se a percepção de riscos no tocante à utilização dos mesmos.

Foram efetuadas 40 entrevistas semi-estruturadas nos próprios estabelecimentos rurais. 0 trabal ho de campo foi realizado no período entre julho e novembro de 1997. As visitas fo- ram feitas semanalmente junto com a equipe da Emater, do Escritório Local de Papucaia.

Foram realizadas 20 visitas ao campo. 0 número de entrevistas al ternou entre o mínimo de uma até cinco em uma mesma visita. A duração das entrevistas variava de acordo com os agricultores, podendo durar de meia hora até três horas. Três visitas foram feitas acompanhadas pelo médico veterinário da Emater, e as demais, pelo engenheiro-agrônomo.

As 20 idas ao campo que resultaram em entrevistas foram classificadas neste trabalho como "visitas" ou "campanhas", servindo como exemplo destas últimas a campanha da febre aftosa (setembro de 1997). Assim sendo, não havia uma programação de atendimentos que tivesse como pressuposto a visita periódica a cada uma das comunidades em um determinado espaço de tempo, visando obter uma cobertura total, de forma sistemática, nos dois distritos. As entrevistas abertas realizadas com os profissionais da saúde, da agricultura e do meio ambiente, foram feitas em três dias separados.

A área de cobertura de atendimento do escritório local da Emater em Papucaia abrange 17 comunidades do 2 o e 3 o Distritos de $\mathrm{Ca}$ choeiras de $\mathrm{M}$ acacu. As entrevistas deste trabaIho foram feitas em sete dessas comunidades: vinte e quatro em três glebas ( $C, F$ e G) do Assentamento de São José da Boa M orte, sete na Comunidade de M arubaí, na Nova Ribeira, cinco em Soarinho e quatro na Comunidade Vecchi. O planejamento de trabalho feito pelo escritório local da Emater é que determinou quais as localidades que deveriam ser visitadas para a realização das entrevistas. Segundo informações obtidas no referido local, os atendimentos (ou contatos com a comunidade de produtores) podem ser classificados em 18 tipos, denominados "métodos de extensão", tais como: "reunião", "visita", "curso", "campanha", "demonstração de método", etc.

A Emater é um órgão do Governo do Estado do Rio de Janeiro que presta serviço de extensão no meio rural, e a sua intermediação foi uma importante estratégia de entrada no campo, pois o fato de termos sido apresentados pelos profissionais da Emater local, conhecedores da região e das pessoas da comunidade, em muito facilitou o trabalho de pesquisa.

Durante as visitas às propriedades, o critério de escolha dos informantes foi aleatório não importando o sexo, mas um representante, agricultor ou agricultora, que se dispusesse a 
responder o questionário, no momento da entrevista, sobre a prática de uso dos agrotóxicos.

\section{Resultados}

Analisando o perfil dos entrevistados, verificamos que $35 \%$ situam-se na faixa etária entre 40 e 50 anos.

Quanto à escolaridade, $25 \%$ dos entrevistados estudaram até a 4 a série do ensino fundamental e $22,5 \%$ eram analfabetos.

Q uanto à condição do produtor, verificamos que $87,5 \%$ eram proprietários e $12,5 \%$ eram empregados. A região pesquisada apresentou características próprias de pequenas propriedades que praticam a agricultura familiar. Identificamos que $45 \%$ das propriedades investigadas possuíam até 10 hectares.

Q uanto à infra-estrutura da região pesquisada, verificamos que $55 \%$ do abastecimento de água é feito por sistema de poço; $25 \%$ usam água tratada pela Cedae (Companhia Estadual de Água e Esgoto), na localidade do Assentamento de São J osé da Boa M orte; $17,5 \%$ usam água de nascente e 2,5\% usam água de outras procedências (captação de rio).

Q uanto ao sistema de esgotamento sanitário: $60 \%$ é feito por fossa, $20 \%$ por sumidouro e $20 \%$ a céu aberto.

$\mathrm{Na}$ área rural, não existe sistema de col eta de lixo feita pela prefeitura e $52 \%$ dos entrevistados disseram que queimam o lixo, 2,5\% o enterram e 42,5\% o levam para o lixão de Japuíba.
Dos estabel ecimentos rurais investigados, $52,5 \%$ têm como atividade econômica, exclusivamente, a agricultura; sendo que $22,5 \%$ praticam a agricultura e a pecuária consorciada, $20 \%$ praticam só a pecuária e $5 \%$ não responderam.

$\mathrm{Na}$ tabela 1, reunimos as respostas referentes à questão dos problemas vivenciados pelos agricultores. É interessante notar que nenhum dos entrevistados identificou o uso de agrotóxicos como um problema para a região. Esses agricultores não incluíram os agrotóxicos no rol de problemas vivenciados no trabalho e no modo de vida, quando solicitados a falar sobre os mesmos de forma espontânea.

Quanto ao preparo do solo para um novo cultivo, os agricultores da região pesquisada não mencionaram a utilização de nenhuma prática de conservação do solo.

Perguntamos aos agricultores se eles conheciam algum outro método de controle de pragas que não fosse agrotóxico. Verificamos que $55 \%$ dos entrevistados desconheciam outro método, que $20 \%$ conheciam e $25 \%$ não responderam.

Dos que conheciam outro método de controle de pragas, $12,5 \%$ disseram que utilizavam a rotação de cultura como uma prática de redução do uso de agrotóxicos: 5\% utilizavam o fumo nas culturas, 2,5\%, o controle biológico e $2,5 \%$ usavam o sabão em pó em vez de agrotóxicos.

U ma percentagem de $82,5 \%$ dos entrevistados declararam saber da existência de pragas

\section{Tabela 1}

Problemas vivenciados pelos agricultores entrevistados.

\begin{tabular}{lcc}
\hline Problema & No de ocorrência & Percentual (\%) \\
\hline Péssimas estradas, quando chove muito & 15 & 37,0 \\
Falta de transporte, pouco horário dos ônibus & 9 & 22,5 \\
Falta de drenagem, alaga a plantação & 7 & 17,5 \\
Falta de energia elétrica & 6 & 15,0 \\
Não tem como escoar a produção & 3 & 7,5 \\
Pragas na plantação & 3 & 7,5 \\
Falta de preço e de incentivo & 2 & 5,0 \\
Falta de apoio do Governo para plantar & 2 & 5,0 \\
Preço da mercadoria não está bom, é muito baixo & 2 & 5,0 \\
Falta médico no posto de saúde & 2 & 5,0 \\
Falta de lazer & 2 & 5,0 \\
A terra não é boa, não é produtiva & 2 & 5,0 \\
Falta de comunicação, telefonia rural & 1 & 2,5 \\
Falta de limpeza da vala entupida & 1 & 2,5 \\
\hline
\end{tabular}


nas lavouras, $10 \%$ não responderam e 7,5\% disseram que não ter problemas com pragas na plantação.

Entre as pragas citadas pelos produtores, destacamos a lagarta, o pulgão, a mosca branca e os carrapatos nos bovinos.

\section{U so de agrotóxicos}

Quanto às propriedades rurais, entre aquelas que foram investigadas, 92,5\% utilizavam agrotóxicos e 7,5\%, não. Duas propriedades, dentre as que não usavam o produto, eram estabelecimentos que praticavam apenas a pecuária. Além disso, os entrevistados não consideravam os produtos empregados no combate aos ectoparasitas no gado como substâncias que podiam causar danos à saúde.

$\mathrm{Na}$ concepção destes trabal hadores rurais só são considerados agrotóxicos os produtos específicos de combate às pragas das plantações.

0 produto mais utilizado nas plantações é - Decis $25 \mathrm{CE}$, com uma percentagem de $65 \%$ de uso entre os entrevistados. Segundo o Compêndio de D efensivos Agrícolas (1993), o Decis 25 CE é um inseticida pertencente ao grupo dos piretróides, de classe toxicológica II.

0 segundo produto mais empregado nos estabel ecimentos rurais investigados é o Gramoxone (42,5\%), herbicida de classe toxicológica I, do grupo químico dos Bipiridilios, o Paraquat.

Nos estabelecimentos que praticam agricultura foram encontrados durante as pesquisas de campo, 25 nomes de produtos comerciais empregados no controle de pragas (Tabela 2).

As pesquisas indicaram que $37,5 \%$ dos entrevistados cal culavam a quantidade utilizada do produto de acordo com o rótulo, $20 \%$ são orientados no cálculo pelo agrônomo e os demais não responderam.

Foi difícil analisar a quantidade dos produtos usados porque os agricultores não têm um critério de dosagem em relação ao tipo de cultura e ao tamanho da plantação. Eles utilizam os agrotóxicos de maneira inadequada e, na maioria das vezes, não respeitando o período de carência. Empregam produtos não específicos para uma determinada praga ou doença, e ainda fazem "coquetéis de agrotóxicos", misturando produtos de diferentes composições químicas.

Alguns agricultores colocam uma quantidade maior do que aquela indicada pelo rótulo do produto. Outros relacionam a quantidade usada com a extensão da infestação da praga e outros disseram quejá têm a dosagem certa ( 10 $\mathrm{ml}$ para 20 litros).

D os entrevistados, $52,5 \%$ liam os rótulos do produto e $47,5 \%$ não liam. Dentre os que não liam os rótulos, 30\% não o faziam por falta de vontade, $15 \%$ não sabiam ler, $5 \%$ não achavam importante e 2,5\% disseram não enxergar a letra, por ser muito pequena.

Em relação à freqüência da aplicação dos agrotóxicos, 35\% disseram que aplicavam toda semana e 25,5\% aplicavam duas vezes ao mês.

Quanto ao tempo gasto durante o dia na aplicação de agrotóxicos, 13 dos entrevistados relataram que gastavam mais de quatro horas nessa tarefa. Em relação às condições do tempo, todos os agricultores entrevistados tinham o critério de só pulverizar as plantações com agrotóxicos se o tempo estivesse bom; em caso de chuva ou muito vento, eles preferiam evitar a aplicação do produto.

Cerca de $85 \%$ dos agicultores aplicavam e preparavam o produto, $12,5 \%$ não responderam e $2,5 \%$ possuíam um empregado que aplicava e outro que misturava o agrotóxico.

Durante a aplicação do agrotóxico, 90\% dos entrevistados disseram apenas aplicar 0 produto, sem fumar e sem nada comer durante a aplicação, e 10\% não responderam.

A pós a aplicação dos agrotóxicos, $45 \%$ desses trabalhadores rurais tomavam banho, 20\% só mudavam de roupa, $17,5 \%$ disseram que tomavam um copo de leite e $17,5 \%$ não tomavam cuidado nenhum.

Quanto à indicação do tipo de agrotóxico utilizado, $40 \%$ utilizavam o produto indicado pelo agrônomo; $15 \%$, pelo vendedor da loja; $12,5 \%$, sugerido por outro agricultor e $7,5 \%$ era o proprietário das terras onde trabal havam que indicava o produto a ser comprado; $85 \%$ dos entrevistados disseram que não precisavam do receituário para comprar agrotóxicos, mesmos os mais tóxicos; $5 \%$ já tinham a receita e $10 \%$ não responderam.

Para a armazenagem dos agrotóxicos, $47,5 \%$ dos agricultores o faziam em local separado; $22,5 \%$ colocavam o produto junto com outros materiais, $14 \%$ guardavam em diferentes lugares como: na moita de bambu, ao ar livre, na varanda ou na roça. Só $5 \%$ dos entrevistados guardavam na própria residência e $10 \%$ não responderam.

Em relação ao destino das embalagens, $27,5 \%$ queimavam as embalagens, $27,5 \%$ jogavam fora no rio ou no mato, $25 \%$ enterravam 
Agrotóxicos nas propriedades que praticam a agricultura.

\begin{tabular}{|c|c|c|c|c|c|}
\hline Nome Comercial & $\begin{array}{l}\text { № de } \\
\text { Ocorrência }\end{array}$ & Percentual (\%) & Composição Química & $\begin{array}{l}\text { Tipo Classe } \\
\text { deAgrotóxico }\end{array}$ & $\begin{array}{l}\text { Classe } \\
\text { Toxicológica }\end{array}$ \\
\hline Decis $25 \mathrm{CE}$ & 26 & 65,0 & Piretróide & Inseticida & II \\
\hline Gramoxone & 17 & 42,5 & Bipiridilios Paraquat & Herbicida & 1 \\
\hline M anzate & 13 & 32,5 & Ditiocarbamato M ancozeb & Fungicida & III \\
\hline Tamaron BR & 12 & 30,0 & $\begin{array}{l}\text { Organofosforado } \\
\text { M ethanidophos }\end{array}$ & Inseticida Acaricida & 1 \\
\hline Roundup & 12 & 30,0 & Derivado de glicina & Herbicida & II \\
\hline Reconil & 3 & 7,5 & Cúprico & Fungicida Bactericida & IV \\
\hline Cercomil PM & 3 & 7,5 & Chlorothalonil & Fungicida & II \\
\hline Afugan & 3 & 7,5 & Organofosforado & Fungicida Inseticida & II \\
\hline Microsol & 2 & 5,0 & Enxofre & Fungicida Acaricida & IV \\
\hline Folidol & 2 & 5,0 & $\begin{array}{l}\text { Organofosforado } \\
\text { Parathion M ethyl }\end{array}$ & Inseticida Acaricida & I \\
\hline Thiovit & 2 & 5,0 & Enxofre & Fungicida Acaricida & IV \\
\hline M eothrin 300 & 2 & 5,0 & Fenpropethrin & Inseticida Acaricida & 1 \\
\hline Daconil 500 & 2 & 5,0 & Chlorothalonil & Fungicida & 1 \\
\hline Malathion & 2 & 5,0 & Organofosforado & Inseticida & III \\
\hline $\begin{array}{l}\text { Isca para Formiga } \\
\text { (granulado) }\end{array}$ & 1 & 2,5 & Sulfonamide & Inseticida & IV \\
\hline Recop & 1 & 2,5 & Cúprico & Fungicida Acaricida & IV \\
\hline Thiodan & 1 & 2,5 & Organoclorado Endosulfan & Inseticida Acaricida & 1 \\
\hline Trigard 750 & 1 & 2,5 & Grupo de triazinas & Inseticida & IV \\
\hline Ridomil & 1 & 2,5 & Ditiocarbamatos Alaninatos & Fungicida & II \\
\hline Benlate & 1 & 2,5 & Benzimidazóis & Fungicida & III \\
\hline Dipel & 1 & 2,5 & Produto Biológico & Inseticida & IV \\
\hline Sevin $480 \mathrm{SC}$ & 1 & 2,5 & Carbamato & Inseticida & II \\
\hline Dipterex I & 1 & 2,5 & Organofosforado richlorfon & Inseticida & II \\
\hline Trichlorfon & 1 & 2,5 & Organofosforado & Inseticida & II \\
\hline Curzatem & 1 & 2,5 & $\begin{array}{l}\text { Grupo de Acetaminas } \\
\text { Ditiocarbamatos }\end{array}$ & Fungicida & III \\
\hline
\end{tabular}

as embalagens, enquanto apenas um entrevistado assumiu reaproveitá-las, e os demais não responderam.

Na região pesquisada, $75 \%$ dos agricultores utilizavam, como equipamento mecânico para a aplicação dos agrotóxicos, o pulverizador costal manual. Só $5 \%$ utilizavam o pulverizador estacionário motorizado, 15\% utilizavam os dois tipos de equipamentos nas suas propriedades e $5 \%$ não responderam.

Quanto ao local de lavagem dos equipamentos, só $5 \%$ dos entrevistados possuíam um tanque próprio para lavagem, 7,5\% não lavavam o equipamento, enquanto que $72 \%$ dos agricultores o faziam na própria lavoura, em valões, nos riachos ou no próprio terreno onde moravam.

Em relação à autoproteção na aplicação de agrotóxicos, $82,5 \%$ dos agricultores não utilizavam EPI (Equipamento de proteção Indivi- dual) completo e 17,5\% o utilizavam. Desses agricultores, 35\% não usavam nenhum tipo de proteção, manuseavam o agrotóxico só de short e descalços, $12,5 \%$ usavam botas, short e chapéu, e 10\% usavam macacão e bota (Tabela 3).

0 motivo alegado pela maioria dos trabaIhadores para não usar os EPI é que a região é muito quente, tornando o equipamento desconfortável.

Constatou-se que $60 \%$ desses agricultores não recebem nenhum tipo de treinamento para a utilização dos agrotóxicos; $25 \%$ recebem treinamento e 15\% não responderam.

Dos agricultores que tiveram treinamento, quatro trabalhadores disseram ter feito um treinamento no Incra há mais de dez anos, na época da implantação do assentamento de São José da Boa M orte.

Em relação à assistência técnica, $67,5 \%$ dos entrevistados recebem assistência técnica da 
Tabela 3

U so de Equipamento de Proteção Individual - EPI.

\begin{tabular}{lcc}
\hline EPI & $\begin{array}{c}\text { No de } \\
\text { Ocorrência }\end{array}$ & $\begin{array}{c}\text { Percentual } \\
\text { (\%) }\end{array}$ \\
\hline Não usam (short, descalços) & 13 & 32,5 \\
Usam completo & 7 & 17,5 \\
(bota, chapéu, macacão, & & \\
luva e máscara) & & \\
Bota e chapéu & 5 & 12,5 \\
Bota e macacão & 4 & 10,0 \\
Bota, calça comprida & 3 & 7,5 \\
e camisa & & \\
Não responderam & 3 & 7,5 \\
Bota elenço no rosto & 2 & 5,0 \\
Bota, luva e lenço no rosto & 1 & 2,5 \\
Tênis, camisa, boné e lenço & 1 & 2,5 \\
no rosto & & \\
Bota, macacão e boné & 1 & $\mathbf{2 , 5}$ \\
Total & $\mathbf{4 0}$ & $\mathbf{1 0 0 , 0}$
\end{tabular}

Emater, 15\% não recebem nenhuma assistência técnica, $10 \%$ recebem do Incra, 2,5\% recebem assistência técnica da Idaco (organização não-governamental que atua no assentamento), e $5 \%$ dos entrevistados não responderam.

Observou-se que $22,5 \%$ dos agricultores entrevistados relataram ter sofrido intoxicação por agrotóxicos. Os sintomas mais comuns mencionados pelos agricultores ao se intoxicarem são: tonteira, dor de cabeça, dor no corpo e visão turva (Tabela 4).

Segundo os entrevistados, $62,5 \%$ conhecem alguma pessoa que passou mal utilizando agrotóxico, 27,5\% disseram que não conhecem ninguém e $10 \%$ não responderam.

Identificamos que os agrotóxicos que mais causaram intoxicação na região foram: Gramoxone, Tamaron BR, Decis 25, M eothrin 300, Rhodiatox e Roundup.

No que tange à observação de animais mortos após a aplicação dos pesticidas, $50 \%$ dos entrevistados não observaram nenhum animal morto. D os agricultores que observaram a existência de animais mortos, $25 \%$ notaram só a presença de insetos e 7,5\%, a morte de passarinhos.

Dos entrevistados, $5 \%$ observaram a ocorrência de morte de peixes no açude que, segundo um agricultor, foi causada pelo Roundup; $12,5 \%$ não responderam.

\section{Percepção do risco no uso de agrotóxicos}

Na percepção do risco à saúde e ao meio ambiente, os agricultores foram divididos em categorias.

Há uma categoria de trabalhadores rurais que não percebe o risco causado à saúde e ao meio ambiente pelo uso de agrotóxicos (27\%). Para esse grupo, o agrotóxico não é um vilão, é a solução mais prática e eficiente no combate às pragas e também a de menor custo.

Podemos observar no relato desse agricultor de Vechi, de 32 anos, com ensino fundamental completo: É mais barato e mais rápido colocar o herbicida (Tordon 2,4-D) do que pagar um empregado para capinar. 0 empregado vai levar quase 30 dias para capinar, dependendo do tamanho da área.

0 segundo grupo reconhece o risco da utilização dos agrotóxicos, mas não se dispõe a mudar (70\%). Ao entrevistarmos um agricultor de São J osé da Boa M orte, de 45 anos, e perguntarmos se ele já tinha sentido al guma coisa ao usar 0 agrotóxico, ele respondeu: Sim, já tive quase morrendo... Faltou 0 ar, queimação, tonteira... Foi o Gramoxone. Não tem solução, só com o uso do agrotóxico.

Essa categoria de trabalhadores reconhece o risco, mas não propõe mudanças, estão conformados em continuar se intoxicando com os agroquímicos.

A terceira categoria de trabalhadores reconhece o risco depois de sofrer uma intoxicação aguda por agrotóxicos (3\%). Essa categoria percebe e evita outra intoxicação, quando muda para um tipo de plantação que requer pouco ou nenhum agrotóxico. Essa foi a única categoria que utilizou a pal avra veneno em relação aos agrotóxicos.

$\mathrm{Na}$ fala de um agricultor de São J osé da Boa M orte, de 52 anos, observamos o temor pelo risco: Eu vi a morte de perto... N ão uso mais esse veneno... A boca ficou seca, sem saliva, a pressão abaixou, a vista escureceu e eu quase morri!

No que diz respeito à percepção dos danos do agrotóxico ao meio ambiente, os agricultores entrevistados não percebem o impacto causado por estes. Eles adotam, de forma generalizada, o uso dos agrotóxicos e não conhecem outra forma de combater as pragas.

Esses agricultores são de uma geração dependente de insumos químicos na agricultura, são filhos dos agricultores que utilizavam os organoclorados. São da geração dos que 
usam os piretróides, organofosforados e carbamatos.

Ao entrevistarmos esses agricultores, identificamos que $97,5 \%$ chamam os agrotóxicos de "remédio".

N essa concepção, os remédios não fazem mal e podem ser usados à vontade, sem proteção e sem risco. Para esses agricultores, os agrotóxicos estão "remediando" porque combatem as pragas. Foi encontrado somente um agricultor consciente de que o agrotóxico era um veneno, que matava as pragas e podia matar as pessoas também. Encontramos outro grupo de usários do produto, que dizia precisar usar cada vez mais "remédio" para combater as pragas. Esses agricultores não percebiam a resistência adquirida pelas pragas por causa da utilização inadequada do produto.

É interessante notar que $62,5 \%$ dos entrevistados, apesar de conhecerem al guém que foi intoxicado por agrotóxicos, não consideraram esses produtos como um problema na região.

Os dados obtidos por este trabalho concordam, em geral, com constatações feitas por outros autores, em pesquisas com grupos de agricultores em diferentes partes do Brasil, no que diz respeito às facilidades para obtenção dos produtos, o seu mau uso e os relatos freqüentes de intoxicações (Araújo et al., 2000; OliveiraSilva et al., 2001; Brega et al., 1998; Paumgarten et al., 1998; Faria et al., 1999; M oreira et al., 2001; Sarcinelli, 2003). Os resultados do trabaIho, revelados principalmente no percentual dos usuários que se expõem desnecessariamente a intoxicações, são também em parte similares às verificações feitas com agricultores de outros países em desenvolvimento (Popper et al., 1993; M cD ougall, 1993; M cConnel \& H ruska, 1993; M wanthi, 1993; Stewart, 1996; Tinoco-Ojanguren \& $\mathrm{H}$ alperin, 1998) ou com aqueles de países já desenvolvidos (Garry, 1994; Labont, 1989).

Também foi constatado um baixo índice de conscientização sobre os riscos inerentes ao uso dos produtos que, quase sempre, era considerado inevitável. A origem desta visão determinista dos trabalhadores, em relação à sua de-
Tabela 4

Sintomas relatados pelos nove agricultores intoxicados.

\begin{tabular}{lcc}
\hline Sintomas & $\begin{array}{c}\text { No de } \\
\text { Ocorrência }\end{array}$ & $\begin{array}{c}\text { Percentual } \\
\text { (\%) }\end{array}$ \\
\hline Tonteira & 9 & 100,0 \\
Dor de cabeça & 7 & 77,7 \\
Dor no corpo & 6 & 66,6 \\
Visão turva & 5 & 55,5 \\
Dor de coluna & 5 & 55,5 \\
Dor de estômago & 4 & 44,4 \\
Queimação & 4 & 44,4 \\
Falta de ar & 2 & 22,2 \\
Vômitos & 2 & 22,2 \\
Dor nas juntas & 2 & 22,2 \\
Infecção nos rins & 2 & 22,2 \\
Urticária & 1 & 11,1 \\
Tremores & 1 & 11,1 \\
Cansaço & 1 & 11,1 \\
Pressão alta & 1 & 11,1 \\
Problemas de fígado & 1 & 11,1 \\
\hline
\end{tabular}

pendência dos agrotóxicos, foi analisada por outros autores como sendo resultado do discurso de fabricantes e comerciantes, de técnicos, que justificam a necessidade pelos interesses comerciais envolvidos (Peres et al., 2001). Entretanto, M oreira et al. (2001) enfatizam a complexidade das questões implicadas na exposição aos agrotóxicos, com uma multiplicidade de rotas cuja compreensão demanda uma avaliação integrada. Além da pressão da propaganda, já mencionada, teriam um papel importante a precariedade das políticas de fiscalização e acompanhamento técnico; a dificuldade de entendimento das informações por parte dos usuários e o desconhecimento de técnicas alternativas e eficientes de cultivo (M oreira et al., loc. cit).

Acreditamos que devido à natureza multifacetada do problema do uso abusivo de agrotóxicos no País, dos riscos para o meio ambiente e para a saúde humana por eles produzidos, apenas uma ação multissetorial de médio a longo prazo seria capaz de reduzir os impactos negativos destas substâncias. 


\section{Colaboradores}

JSM Castro foi a responsável pela coleta e análise dos dados de campo e pela redação do texto; eU Confalonieri, pelo desenho da pesquisa e pela revisão do texto para publicação.

\section{Referências bibliográficas}

Anvisa 2002. Programa de Análise de Resíduos de Agrotóxicos em Alimentos: relatório anual 04/06/200130/06/2002. Agência N acional de Vigilância Sanitária, Brasília.

Araújo ACP et al. 2000. Impacto dos praguicidas na saúde: estudo da cultura de tomate. Revista de Saúde Pública 34(3):309-313.

Bortoletto ME 1990. Tóxicos, civilização e saúde. Contribuição à análise dos sistemas de informações tóxicofarmacológicas no Brasil. Fundação Oswaldo Cruz, Rio de Janeiro.

Brasil. M inistério da Saúde, Secretaria de Vigilância Sanitária 1997. M anual de vigilância da saúde de populações expostas a agrotóxicos. Organização Pan-Americana da Saúde, Brasília.

Brega SM et al. 1998. Clinical, cytogenetic and toxicological studies in rural workers exposed to pesticides in Botucatu, São Paulo, Brazil. Caderno de Saúde Pública 14(Supl. 3):109-115.

Faria N M X et al. 1999. Estudo transversal sobre saúde mental de agricultores da Serra Gaúcha (Brasil). Revista de Saúde Pública 33(4):391-400.

Garry VF, Kelly JT, Sprafka JM, Eduards S \& Griffith J 1994. Survey of health and use characterization of pesticide appliers in M inesota. Archives of Environmental Health 49(5):337-343.

Guillette EA et al. 1998. An anthropological approach to the evolution of pre-school children exposed to pesticides in M exico. Envir. Health Perspect. 106(6):347353.

Igbedioh SO 1991. Effects of agricultural pesticides on humans, animal and higher plants in developing countries. Archives of Environmental Health 46(4): 218-223.

Labont RN 1989. Pesticides and healthy public policy. Canadian Journal of Public Health 80:231-242.

M cConnell R \& H ruska AJ 1993. An epidemic of pesticide poisoning in Nicaragua: implications for prevention in developing countries. A. M. J. Public Health 83 (11):1.559-1.562.

M CD ougall L et al. 1993 Actitudes and practices of pesticide uses in Saint Lucia, West Indies. Bulletins of PAHO 27(1):43-51.

M oreira JC et al. 2001. U ma avaliação integrada do impacto do uso de agrotóxicos sobre a saúde humana em uma comunidade agrícola de Nova Friburgo. Ciência Saúde Coletiva 7(2):299-311.

M wanthi AM , M seh SB \& Kimani NV 1993. Patterns of agrochemical handling and community Response in Central Kenya. Journal of Environmental H ealth 11.
Oliveira-Silva JJ et al. 2001. Influência dos fatores socioeconômicos na contaminação por agrotóxicos, Brasil. Revista de Saúde Pública 35(2):130-135.

Paumgarten FJR et al. 1998. Levels of organochlorine pesticides in the blood serum of agricultural workers from the State of Rio de Janeiro, Brazil. Cadernos de Saúde Pública 14(Supl. 3):33-39.

Peres $\mathrm{F}$ et al. 2001. Comunicação relacionada ao uso de agrotóxicos em uma região agrícola do Estado do Rio de Janeiro. Revista de Saúde Pública 35(6):564-570.

Peres F \& M oreira JC (orgs.) 2003. É veneno ou é remédio? Agrotóxicos, saúde eambiente. Fiocruz, Rio de Janeiro.

Popper R, Andino K, Bustamante M , H ernandez B \& Rodos $L$ 1996. Knowledge and beliefs regarding agricultural pesticides in rural Guatemala. Environmental M anagement 20(2):241-248.

Rozemberg B 1994. O consumo de calmantes e o "proble ma de nervos" entre lavradores. Revista de Saúde Pública 2(4):300-308.

Sarcinelli PN 2003. A exposição de crianças eadolescentes a agrotóxicos, pp. 43-58. In F Peres \& JC M oreira (orgs.). É veneno ou é remédio. Agrotóxicos, saúde e ambiente. Fiocruz, Rio de Janeiro.

Sartorato CR 1996. D ominação versus resistência: os agrotóxicos nas lavouras dos sem-terra. Representação social dos riscos à saúde dos trabalhadores. Dissertação de mestrado. CESTEH/EN SP/Fiocruz, Rio de Janeiro.

Siqueira M L, Jacob A \& Canhete RL 1983. Diagnóstico dos problemas ecotoxicológicos causados pelo uso de defensivos agrícolas no Estado do Paraná. Revista Brasileira de Saúde 0 cupacional 11(44):7-17.

Stewart DJ 1996. Pesticide use, habits and health aware ness among Egyptian Farmers. AM BIO 25(6):425426.

Tinoco-Ojanguren R \& H alperin DC 1998. Poverty, production and health: inhibition of erythocyte cholinesterase via occupational exposure to organophosphate insecticides in Chiapas, M exico. Arch. Envir. Health 53(1):29-35.

Trapé AZ 1993. 0 caso dos agrotóxicos, pp. 565-593. In Rocha et al. Isto é trabalho de gente? Vida, doença e trabalho no Brasil. Ed. Vozes, Petrópolis.

Artigo apresentado em 19/08/2004

Aprovado em 15/09/2004

Versão final apresentada em 12/10/2004 